\title{
Selection of a New Highly Resistant Strain for Malolactic Fermentation under Difficult Conditions
}

\author{
R. Guzzon ${ }^{1 *}$, E. Poznanski ${ }^{1}$, L. Conterno ${ }^{1}$, P. Vagnoli ${ }^{2}$, S. Krieger-Weber ${ }^{3}$ and A. Cavazza ${ }^{1}$ \\ (1) Fondazione Edmund Mach, Via Edmund Mach 1, 38010 San Michele all'Adige (TN), Italy \\ (2) Lallemand Italiana, Castel d'Azzano (VR), Italy \\ (3) Lallemand Inc., Canada
}

Date of submission for publication: June 2009

Date of acceptance for publication: October 2009

Key words: Oenococcus oeni, malolactic fermentation, sulphur dioxide, resistance limiting factors, bacteria selection, multi-strain starter

\begin{abstract}
Malolactic fermentation (MLF) is a biological process that contributes to wine quality, but it is frequently affected by various vinification conditions. Resistance to four wine-limiting factors was studied with respect to 10 Oenococcus oeni strains in order to select a suitable strain for performing reliable MLF in difficult wines. Resistance to low fermentation temperature, high $\mathrm{SO}_{2}$ and/or ethanol concentration, and low $\mathrm{pH}$ were assayed in laboratory tests. A pool of the most resistant strains was used in a set of laboratory MLFs. At the end of fermentation, the dominant strains were identified by RAPD-PCR. The PN4 strain was found to be dominant in the majority of cases and under the most detrimental wine conditions, and it was therefore chosen as the single-strain inoculum for the subsequent MLF trials. The effectiveness of the PN4 strain was confirmed in a series of MLFs carried out in three different countries under experimental and industrial conditions. It accomplished MLF in wines with up to $15.8 \%$ ethanol, $\mathrm{pH}$ as low as 3.0, $60 \mathrm{mg} / \mathrm{L}$ of free $\mathrm{SO}_{2}$, and in fermentation temperatures below $17^{\circ} \mathrm{C}$. Our findings indicate that the $O$. oeni PN4 strain could be an effective starter, guaranteeing regular and reliable MLF fermentation.
\end{abstract}

Malolactic fermentation (MLF) affects wine quality not only by lowering total wine acidity, but also by improving sensorial properties and biological stability. These beneficial effects depend on the bacteria strain involved in MLF and on the type of wine (Lonvaud-Funel, 1999; Liu, 2002; Renouf et al., 2006). Many lactic acid bacteria (LAB) species are involved in the conversion of malic acid to lactic acid, although Oenococcus oeni is the predominant species in wine (Wibowo et al., 1985; Bartowsky \& Henschke, 1999). Even though MLF can occur spontaneously in wines, its evolution is not predictable; the use of malolactic starters is therefore a useful practice in wine making (Davis et al., 1988; Bauer \& Dicks, 2004). Many researchers have investigated the evolution of MLF in wine, with respect to low $\mathrm{pH}$ (Guzzo et al., 2002; Zapparoli et al., 2006), high ethanol or sulphur dioxide concentrations (Teixeira et al., 2002; Da Silveira et al., 2004; Reguant et al., 2005; Carrete et al., 2006a), and low fermentation temperatures (Ribéreau-Gayon et al., 2004) as factors limiting LAB activity in wine.

In this work, we investigate the performance of 10 strains of $O$. oeni isolated from spontaneous MLF in order to select a malolactic starter strain resistant to the most significant limiting factors in wine. An original, two-step approach to bacteria selection was taken: after preliminary characterisation of each strain's resistance to various wine-limiting factors (ethanol and sulphur dioxide concentration, wine $\mathrm{pH}$ and low fermentation temperature), a pool of the most resistant strains was used as a mixed-culture starter to induce malolactic fermentation. RAPD-PCR characterisation of $O$. oeni strains isolated at the end of MLF identified the dominant strains, which were then characterised according to their individual resistance to wine-limiting conditions. Finally, a single strain was chosen for further MLF trials and laboratory results were confirmed by 44 MLFs carried out in wines produced in Italy, Germany and California.

\section{MATERIALS AND METHODS}

\section{$O$. oeni isolation, characterisation and physiological tests}

O. oeni strains were isolated from wines made in five wineries in the Province of Trento (Italy) after spontaneous MLF (malic acid concentration $<0.5 \mathrm{~g} / \mathrm{L}$ ). Isolated $\mathrm{LAB}$ strains were identified as $O$. oeni by species-specific PCR (Zapparoli et al., 1998). The type strain $O$. oeni DSMZ 20252 (Deutsche Sammlung von Mikroorganismen und Zellkulturen, D) was also included. Strains identified as $O$. oeni were typed by RAPD-PCR using the primers M13, PC1 and GTG5 (Versalovic et al., 1994; Bartowsky \& Henschke, 1999; Giraffa et al., 2000). PCR was performed using an MJ Research PTC-200 Peltier thermal cycler at a final volume of $25 \mu \mathrm{L}$. Master mix was prepared according to Guzzon et al. (2007). The amplification products were resolved by electrophoresis in $2.5 \%(\mathrm{w} / \mathrm{v})$ agarose TAE gels $(40 \mathrm{mmol}$ Trisacetate, 1 mmol EDTA, $\mathrm{pH} 8.0$ ), stained with ethidium bromide, visualised under UV light and photographed. A $1 \mathrm{~Kb}$ DNA ladder (Invitrogen) was used for reference purposes. The electrophoresis patterns were converted, normalised and further analysed with Bionumerics 4.1 software (Applied Maths, Sint-Martens-Latem, Belgium).

Bacterial growth at different ethanol concentrations, $\mathrm{pH}$ levels and incubation temperatures was tested by inoculating $100 \mathrm{~mL}$ of Leuconostoc oenos medium (Atlas, 2004) with 1\% of pure culture 
$\left(10^{6} \mathrm{cell} / \mathrm{mL}\right)$. The composition of the medium was adjusted to 10 , 12,14 or $16 \% \mathrm{v} / \mathrm{v}$ of ethanol (Carlo Erba, Italia), the temperature was set at $15,22,30$ or $37^{\circ} \mathrm{C}$, and the $\mathrm{pH}$ was adjusted to 2.9 , $3.1,3.3$ or 3.5 with $\mathrm{HCl}$ (Carlo Erba, I). Bacterial growth was monitored after 20 days of incubation by measuring the increase in optical density at $600 \mathrm{~nm}\left(\mathrm{OD}_{600}\right)$, using a Hitachi U-2000 spectrophotometer (Hitachi High-Technologies Corporation, Japan).

The effect of $\mathrm{SO}_{2}$ concentration on bacterial activity was tested in pasteurised wine (ethanol $11.5 \% \mathrm{v} / \mathrm{v}, \mathrm{pH} 3.5$, sugars 0.5 $\mathrm{g} / \mathrm{L}$ ) by measuring the production of lactic acid after 20 days of incubation, using FOSS WineScan equipment (FOSS, DK). The concentration of total sulphur dioxide in the wine was adjusted to 20,40 or $60 \mathrm{mg} / \mathrm{L}$ with potassium metabisulphite (Vebi, I).

\section{Laboratory MLF tests with multi-strain $O$. oeni culture}

Eight MLFs were performed in white wine (ethanol 11.6\%, pH 3.3, residual sugars $0.2 \mathrm{~g} / \mathrm{L}$, malic acid $3.5 \mathrm{~g} / \mathrm{L}$, total $\mathrm{SO}_{2} 20 \mathrm{mg} / \mathrm{L}$ ). In each trial, one of the limiting factors being studied (ethanol, $\mathrm{pH}$, fermentation temperature and $\mathrm{SO}_{2}$ ) was modified as described in the physiological tests. The final chemical composition of the wines is reported in Table 1 . The wines were inoculated with a $1 \%$ (v/v) multi-strain culture. The multi-strain culture was composed of six-strain pure cultures. The pure cultures were cultured up to

\section{TABLE 1}

Main parameters of wine inoculated by multi-strain $O$.oeni culture in MLF laboratory tests. Bold numbers indicate the discriminatory values in each trial.

\begin{tabular}{lcccc}
\hline Test & $\begin{array}{c}\text { Ethanol } \\
(\mathbf{\%} \mathbf{v} / \mathbf{v})\end{array}$ & $\mathbf{p H}$ & $\begin{array}{c}\text { Fermentation } \\
\text { temperature }\left({ }^{\circ} \mathbf{C}\right)\end{array}$ & $\begin{array}{c}\mathbf{S O}_{2} \\
(\mathbf{m g} / \mathbf{L})\end{array}$ \\
\hline Standard & 12.0 & 3.30 & 18 & 20 \\
Ethanol - & $\mathbf{1 1 . 2}$ & 3.30 & 18 & 20 \\
Ethanol + & $\mathbf{1 3 . 7}$ & 3.30 & 18 & 20 \\
$\mathrm{pH}-$ & 12.0 & $\mathbf{3 . 1 0}$ & 18 & 20 \\
$\mathrm{pH}+$ & 12.0 & $\mathbf{3 . 5 2}$ & 18 & 20 \\
$\mathrm{Temperature}-$ & 12.0 & 3.30 & $\mathbf{1 5}$ & 20 \\
$\mathrm{SO}_{2}+$ & 12.0 & 3.30 & 18 & $\mathbf{4 0}$ \\
$\mathrm{SO}_{2}++$ & 12.0 & 3.30 & 18 & $\mathbf{6 0}$ \\
\hline
\end{tabular}

the stationary phases in Leuconcostoc oenos medium and then diluted 4:1 with wine. After 48 hours in wine (mean cellular density was $2 \times 10^{8} \mathrm{CFU} / \mathrm{mL}$ ), the six cultures were mixed together to constitute the multi-strain culture, where each strain was equally represented in term of cell density. Bacterial cell density after inoculation in wine was at a ratio of $10^{6} \mathrm{CFU} / \mathrm{mL}$. The evolution of MLF was monitored by FOSS WineScan equipment (FOSS, DK), which measured the decrease in malic acid concentration. At the end of MLF (malic acid $<0.5 \mathrm{~g} / \mathrm{L}$ ), the lactic acid bacteria were counted on Leuconostoc oenos agar medium. Ten colonies were isolated from a plate of each wine and typed by RAPD-PCR, as previously described.

\section{MLF tests with single-strain PN4 culture in the winery}

A freeze-dried preparation of $O$. oeni PN4 MBR ${ }^{\circledR}$ (Lallemand Inc.) was tested in wine and was compared with two other commercial O. oeni $\mathrm{MBR}^{\circledR}$ strains. Viable cell counts of each lyophilised culture were around $2 \times 10^{11} \mathrm{CFU} / \mathrm{g}$, and therefore $1 \mathrm{~g} / 100 \mathrm{~L}$ from each culture was inoculated into the wine to achieve a final cell density about of $2 \times 10^{6} \mathrm{CFU} / \mathrm{mL}$. Spontaneous MLF carried out without LAB inoculum was used as a control. Fermentation was monitored by measuring ethanol, $\mathrm{pH}, \mathrm{SO}_{2}$, total acidity, acetic acid, malic acid and lactic acid with FOSS WineScan equipment (FOSS, DK) and a Crison Titrator (Crison Instrument, E). The number of $O$. oeni cells was ascertained by plate count on Leuconostoc oenos agar medium.

\section{Statistics}

Statistical analyses of the data were carried out using Statistica 7.1 software (StatSoft Inc.). Cluster analysis was carried out using the tree clustering method, in which Euclidean distances between the raw data were computed using the amalgamation rule, UPGMA. The stress conditions showing the highest differences among strains were defined by comparing the relative standard deviation index (RSD). A principal component analysis (PCA) was based on correlations between the variables and the PC scores.

\section{RESULTS}

\section{Isolation and characterization of indigenous $O$. oeni strains}

Ten LAB strains were isolated from spontaneous MLFs in wines from five wineries in the province of Trento; the main chemical parameters are listed in Table 2. Bacteria were isolated from wines with a total $\mathrm{SO}_{2}$ concentration $\geq 30 \mathrm{mg} / \mathrm{L}$ and $\mathrm{pH} \leq 3.5$. Even in this harsh environment, bacterial cells grew beyond

\section{TABLE 2}

Chemical and microbiological features of wines sampled in five wineries (M, P, PN, S, T) from which LABs were isolated.

\begin{tabular}{|c|c|c|c|c|c|c|c|}
\hline Sample code & Wine & pH & $\begin{array}{c}\text { Total } \\
\mathrm{SO}_{2} \\
(\mathrm{mg} / \mathrm{L})\end{array}$ & $\begin{array}{c}\text { Free } \\
\mathrm{SO}_{2} \\
(\mathrm{mg} / \mathrm{L})\end{array}$ & $\begin{array}{l}\text { Total acidity } \\
\text { (g/L of } \\
\text { tartaric acid) }\end{array}$ & $\begin{array}{l}\text { Malic } \\
\text { acid } \\
(\mathrm{g} / \mathrm{L})\end{array}$ & $\begin{array}{c}\text { LAB counts } \\
\left(\times 10^{7} \mathrm{CFU} / \mathrm{mL}\right)\end{array}$ \\
\hline M & Pinot gris & 3.50 & 64 & 12 & 5.0 & 2.4 & 0.2 \\
\hline $\mathrm{P}$ & Teroldego & 3.43 & 62 & 10 & 6.4 & 3.3 & 18.0 \\
\hline PN & Pinot noir & 2.90 & 30 & 2 & 8.4 & 3.8 & 4.2 \\
\hline S-1 & Lagrein & 3.38 & 47 & 14 & 8.8 & 3.4 & 0.1 \\
\hline S-2 & Marzemino & 3.50 & 52 & 17 & 7.2 & 3.4 & 2.3 \\
\hline $\mathrm{T}-1$ & Teroldego & 3.36 & 62 & 19 & 6.4 & 3.3 & 4.2 \\
\hline $\mathrm{T}-2$ & Teroldego & 3.49 & 76 & 25 & 6.0 & 3.7 & 8.1 \\
\hline
\end{tabular}


TABLE 3

Frequencies of isolated $O$. oeni strains in wine after MLF. Strains were typed by RAPD-PCR, comparing the profiles obtained using the primers M13, PC1 and GTG5.

\begin{tabular}{|c|c|c|c|c|c|c|c|c|c|c|c|c|c|}
\hline & Strain code & PN3 & PN4 & M1 & M2 & M3 & P1 & $\mathbf{P 2}$ & P3 & P4 & P5 & & \\
\hline \multirow{4}{*}{ Sample code } & $\mathrm{PN}$ & 5 & 5 & - & - & - & - & - & - & - & - & & \\
\hline & $\mathrm{M}$ & - & - & 8 & 1 & 1 & - & - & - & - & - & & \\
\hline & $\mathrm{P}$ & - & - & - & - & - & 5 & 2 & 1 & 1 & 1 & & \\
\hline & Strain code & S13 & S15 & S16 & S17 & S41 & S42 & S44 & T11 & T12 & T13 & T14 & T15 \\
\hline \multirow{4}{*}{ Sample code } & S-1 & 6 & 1 & 2 & 1 & - & - & - & - & - & - & - & - \\
\hline & $\mathrm{S}-2$ & - & 3 & - & - & 2 & 2 & 3 & - & - & - & - & - \\
\hline & $\mathrm{T}-1$ & - & - & - & - & - & - & - & 3 & 1 & 3 & 2 & 1 \\
\hline & $\mathrm{T}-2$ & - & - & - & - & - & - & - & - & - & 7 & 3 & - \\
\hline
\end{tabular}

$10^{7} \mathrm{CFU} / \mathrm{mL}$ in $70 \%$ of the wines, and malic acid was always consumed in less than 30 days. The dominance of $O$. oeni among the LAB populations in the wines was confirmed with speciesspecific PCR applied to the isolated strains. Table 3 summarises the distribution of $O$. oeni strains in the wine samples after MLF. At least two different $O$. oeni strains were typed by RAPD-PCR in each wine. In several cases, i.e. P, S-1, S-2 and T-1, the wines had a more composite microflora and different strains were present. Assuming that the dominant strains were those best adapted to the wine conditions, the strains that comprised more than the $40 \%$ of each wine population and those that were present in different wines from the same winery were characterised further in the physiological tests.

\section{Physiological tests}

The effects of $\mathrm{SO}_{2}$, ethanol concentration, $\mathrm{pH}$ and fermentation temperature on the activity of $O$. oeni strains were tested in laboratory experiments on Leuconostoc oeni medium (Table 4). Strains were grouped by cluster analysis based on their resistance to the wine-limiting factors. Data were expressed as cell density of the cultures ( $\mathrm{pH}$, ethanol and temperature tests) or as wine lactic acid concentration ( $\mathrm{SO}_{2}$ test). A cluster analysis was performed on the results in order to identify similarities among the strains. The dendrogram generated by this analysis is reported in Fig. 1. Three groups were discriminated amongst the strains: T11, P1, PN3, S13 (1 ${ }^{\text {st }}$ group); T13, T14, PN4 (2 ${ }^{\text {nd }}$ group); and M1, S15, S44 ( $3^{\text {rd }}$ group).

The relative standard deviation index (RSD) indicated that pH 3.3 (RSD: 0.8), ethanol 14\% (RSD: 0.3 ), temperature $15^{\circ} \mathrm{C}$ (RSD: 0.4 ) and $\mathrm{SO}_{2} 40 \mathrm{mg} / \mathrm{L}$ (RSD: 0.8 ) were the values of the four variables that best differentiated the behaviour of the strains studied (bold data in Table 4). The data were also submitted to PCA in order to obtain further information on strain resistance. Fig. 2A shows the spatial distribution of the four variables considered (ethanol $14 \%, \mathrm{pH} 3.3,15^{\circ} \mathrm{C}$ of incubation and $40 \mathrm{mg} / \mathrm{L}$ of $\mathrm{SO}_{2}$ concentration) in the plane defined by factors 1 and 2 . The cumulative percentage of the total variance according to the first two factors was $82.54 \%$; the scatter plot showed a clear effect of $\mathrm{SO}_{2}$ and ethanol concentration, whereas there were no clear $\mathrm{pH}$ and temperature effects. Fig. $2 \mathrm{~B}$ shows the spatial distribution of the 10 strains tested with respect to these variables in the plane defined by factors 1 and 2 . We identified three different groups of strains with homogenous resistance to limiting factors. The first group comprised strains P1, PN3, S13, T11 and T14; the second comprised strains PN4 and T13; and the third group comprised strains M1, S15 and S44. Except for strain T14, placed in group 1 instead of group 2 by PCA, the groups obtained by the two statistical approaches are identical.

\section{Laboratory MLF tests with mixed $O$. oeni culture}

A set of eight experimental MLFs was also carried out in wines in order to investigate MLF in the presence of limiting factors. The chemical parameters of the wines were varied according to the experimental plan, as shown in Table 1, to test the specific effects of each of them. A mixture of six strains was inoculated in the eight wines to allow the most suitable strain of inoculated biomass to grow better in each of the adjusted wine conditions. Two strains from each of the groups obtained from PCA were used for the multi-strain culture: M1, PN3, PN4, S44, T13 and T14. The kinetics of L-malic acid degradation are reported in Figure 3. Only the MLF in the test with the highest $\mathrm{SO}_{2}$ concentration (60 $\mathrm{mg} / \mathrm{L}$ ) got stuck after the consumption of only $1 \mathrm{~g} / \mathrm{L}$ of malic acid, while all the other MLFs were completed in around 30 days. In a less harsh environment ( $\mathrm{pH} 3.5$ and $11.2 \%$ of ethanol), malolactic fermentation was faster and was completed in 20 days. In wines with a high ethanol content $(13.7 \%)$ or at the lowest temperature $\left(15^{\circ} \mathrm{C}\right)$, the fermentation rate was slower and MLF required 26 days for completion. We observed 20 days of lag phase in the tests performed at the lowest $\mathrm{pH}$ (3.1) or in the presence of $40 \mathrm{mg} / \mathrm{L}$ of $\mathrm{SO}_{2}$. In these two cases, MLF required 28 days. Ten were isolated after each fermentation and characterised by RAPD-PCR. Among the six strains composing the multi-strain inoculum, only three, PN4, PN3, and T14, were found at the end of the MLFs (Table 5). In particular, the strain PN4 was present in all MLFs and it was the most frequently isolated strain in five out of eight trials. Another two unknown $O$. oeni strains were found in some fermentations, probably belonging to the native wine microflora.

\section{O. oeni MLF performance in the winery}

Because isolated with the higher frequency at the end of the laboratory MLF tests, PN4 was compared to two commercial 


\section{TABLE 4}

Effect of $\mathrm{pH}$, ethanol, temperature and $\mathrm{SO}_{2}$ on LAB growth and activity. Tests 1 to 12 were performed in Leuconostoc oenos medium, while tests 13 to 15 were performed in wine. O. oeni cell count and lactic acid production after 20 days are reported.

\begin{tabular}{|c|c|c|c|c|c|c|c|c|c|c|c|}
\hline Trial & & T13 & T14 & M1 & S44 & P1 & S13 & S15 & PN4 & PN3 & T11 \\
\hline & pH & \multicolumn{10}{|c|}{ Cell counts $\left(\times 10^{9} \mathrm{CFU} / \mathrm{mL}\right)$} \\
\hline 1 & 2.9 & 0.5 & 0.5 & 0.5 & 0.5 & 0.6 & 0.5 & 0.4 & 0.6 & 0.6 & 0.5 \\
\hline 2 & 3.1 & 0.7 & 0.7 & 0.7 & 0.7 & 0.6 & 0.7 & 0.7 & 0.7 & 0.8 & 0.7 \\
\hline 3 & 3.3 & 0.6 & 0.7 & 3.0 & 3.0 & 0.7 & 0.8 & 3.0 & 0.9 & 0.8 & 0.7 \\
\hline \multirow[t]{2}{*}{4} & 3.5 & 1.2 & 1.6 & 3.0 & 3.0 & 2.4 & 2.9 & 3.0 & 1.2 & 3.0 & 2.8 \\
\hline & Ethanol (\% v/v) & \multicolumn{10}{|c|}{ Cell counts $\left(\times 10^{9} \mathrm{CFU} / \mathrm{mL}\right)$} \\
\hline 5 & 10 & 1.3 & 2.2 & 2.4 & 2.6 & 1.5 & 1.5 & 2.2 & 1.7 & 1.9 & 2.6 \\
\hline 6 & 12 & 1.6 & 1.3 & 1.1 & 1.2 & 1.1 & 1.2 & 1.2 & 1.2 & 1.3 & 1.5 \\
\hline 7 & 14 & 0.8 & 0.6 & 0.6 & 0.7 & 0.6 & 0.4 & 0.8 & 1.0 & 0.9 & 1.0 \\
\hline \multirow[t]{2}{*}{8} & 16 & 0.3 & 0.3 & 0.3 & 0.3 & 0.4 & 0.4 & 0.3 & 0.3 & 0.3 & 0.4 \\
\hline & Temperature $\left({ }^{\circ} \mathrm{C}\right)$ & \multicolumn{10}{|c|}{ Cell counts $\left(\times 10^{9} \mathrm{CFU} / \mathrm{mL}\right)$} \\
\hline 9 & 15 & 1.3 & 1.4 & 3.0 & 3.0 & 1.1 & 1.4 & 3.0 & 1.7 & 1.5 & 1.2 \\
\hline 10 & 22 & 2.5 & 2.6 & 3.0 & 3.0 & 2.7 & 2.7 & 3.0 & 3.0 & 2.7 & 2.6 \\
\hline 11 & 30 & 2.0 & 2.2 & 3.0 & 2.6 & 3.0 & 2.2 & 2.6 & 2.5 & 2.4 & 2.8 \\
\hline \multirow[t]{2}{*}{12} & 37 & 1.0 & 0.1 & 1.4 & 1.4 & 1.0 & 0.9 & 1.4 & 1.0 & 1.4 & 1.2 \\
\hline & $\mathrm{SO}_{2}^{*}(\mathrm{mg} / \mathrm{L})$ & \multicolumn{10}{|c|}{ Lactic acid production (\% of the total amount expected) } \\
\hline 13 & 20 & 94 & 94 & 97 & 100 & 91 & 91 & 91 & 94 & 94 & 91 \\
\hline 14 & 40 & 82 & 85 & 21 & 15 & 15 & 21 & 21 & 100 & 33 & 24 \\
\hline 15 & 60 & 15 & 18 & $<10$ & $<10$ & $<10$ & $<10$ & $<10$ & 10 & 10 & $<10$ \\
\hline
\end{tabular}

* Test performed in wine with $11.5 \% \mathrm{v} / \mathrm{v}$ ethanol, $\mathrm{pH} 3.5$, and residual sugars $<0.5 \mathrm{~g} / \mathrm{L}$.

O. oeni strains in pure culture-inoculated MLFs in the winery (Table 6).

In the trials carried out in Germany, PN4 activity was tested in one white and three red wines. Their $\mathrm{pH}$ ranged between 3.05 and 3.40 , the fermentation temperature was always below $17^{\circ} \mathrm{C}$, and their ethanol content was between 12.0 and $13.5 \%$. In all the wines, spontaneous fermentation was slow or stuck. The commercial strain degraded malic acid more slowly: in MLF 2 and MLF 3 it fermented malic acid in 16 and 10 days respectively, while PN4 degraded malic acid in 12 and 8 days respectively; in MLF 1 the commercial strain failed to complete MLF within 30 days. It was only in MLF 4 that the activities of PN4 and the commercial strain Com1 were comparable.

The PN4 strain was also tested in two wines in the USA. MLF 5 was carried out in a Merlot wine from California with $14.0 \%$ ethanol and $60 \mathrm{mg} / \mathrm{L}$ of $\mathrm{SO}_{2}$. These conditions affected all the MLFs, but PN4 carried out the fermentation in 28 days, whereas the commercial strain Com2 required 32 days. Spontaneous MLF got stuck after the consumption of only $0.5 \mathrm{~g} / \mathrm{L}$ of malic acid. Similar results were observed in MLF 6, carried out in a Long Island Merlot with $14.2 \%$ ethanol and $60 \mathrm{mg} / \mathrm{L}_{\text {of }} \mathrm{SO}_{2}$; despite these severe conditions for bacterial activity, PN4 required 13 days to complete MLF vs. 34 required by the commercial strain.

In central and northern Italy, 32 MLFs were monitored. The results agreed with previous findings: ethanol concentration was frequently the most limiting factor found in wines, ranging from 11.6 to $15.8 \%$.
MLF took longer when the ethanol concentration was above $12.5 \%$. Among the technological variables, i.e. the processing parameters directly manipulated by the winemaker, $\mathrm{SO}_{2}$ appeared to be the most detrimental to bacterial activity. Nevertheless, MLF carried out by PN4 generally appeared to be shorter than spontaneous MLF or MLF driven by commercial strains, showing it to be more suitable for wines with unfavourable conditions.

\section{DISCUSSION}

\section{Effects of environmental conditions on the evolution of malolactic bacteria}

Lactic acid bacteria play a fundamental role in winemaking (PozoBayon et al., 2005; Renouf et al., 2005; Ugliano \& Moio 2007;). Various works have recently been undertaken with the aim of selecting LAB strains able to carry out effective MLF (Costello et al., 2003; Coucheney et al., 2005; Carrete et al., 2006a). In order to isolate efficient MLF starters, the harshest conditions must be tested. Ethanol content and wine $\mathrm{pH}$ are the main wine parameters impacting on bacterial activity (Guzzo et al., 2002; Teixeira et al., 2002; Rosi et al., 2003); in addition, many technological variables, such as fermentation temperature and the amount of sulphur dioxide added to the wine, have a significant impact on the effectiveness of MLF starter cultures (Liu \& Gallander 1983; Reguant et al., 2005; Carrete et al., 2006a,b). Accordingly, in this work LABs were isolated from wines in which MLF was completed in less than 30 days, despite the high $\mathrm{SO}_{2}$ content and a $\mathrm{pH}$ below 3.5 . 


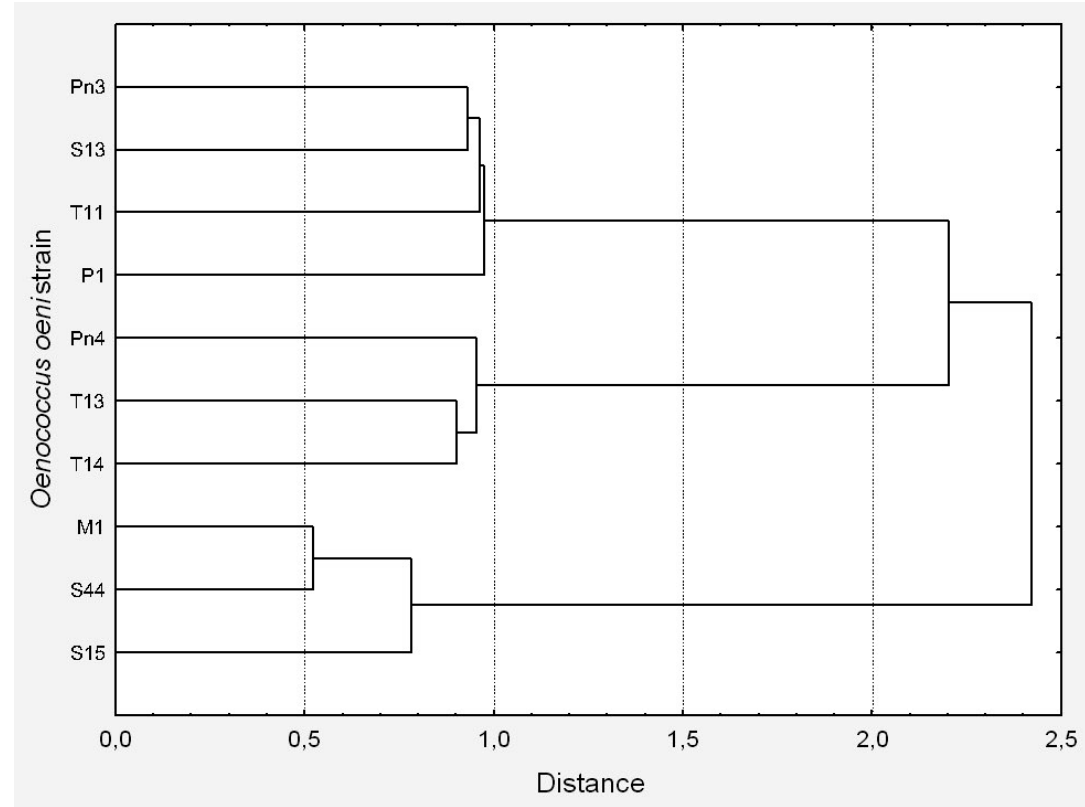

FIGURE 1

Cluster analysis based on $\mathrm{O}$. oeni cell growth or activity in the presence of different limiting factors (ethanol, $\mathrm{pH}, \mathrm{SO}_{2}$ and fermentation temperature - 15 variables) after 20 days of incubation. The distance between strains is indicated by arbitrary units; the groups were separated by 1.0 units.

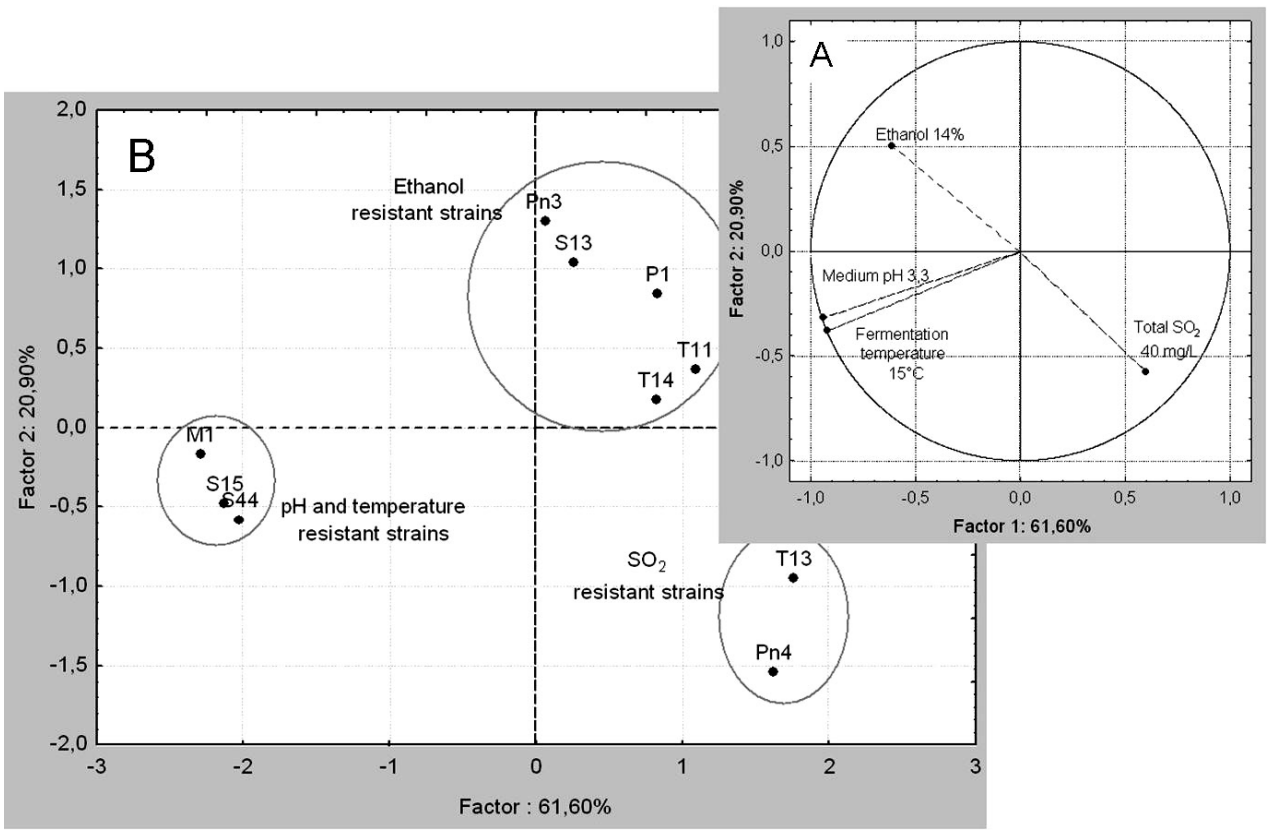

FIGURE 2

PCA of cellular density or lactic acid production in the presence of the most selective $\mathrm{pH}$, ethanol, temperature and $\mathrm{SO}_{2}$ values A. Projection of variables in the factor plane $(1 \times 2)$. B. Scatter plot of 10 cases in the factor plane $(1 \times 2)$.

The onset and kinetics of MLF in wine are closely related to the amount of viable lactic acid bacteria (LAB), which should be higher than the critical value of $10^{6} \mathrm{CFU} / \mathrm{mL}$ (Henick-Kling 1993; Ribéreau-Gayon et al., 2004). The viable cell counts in the wine samples chosen for isolation revealed high LAB densities of up to $10^{7} \mathrm{CFU} / \mathrm{mL}$. All the isolates were identified as $O$. oeni with species-specific PCR methods. These findings are in accordance with previous observations: among the different wine LABs, $O$. oeni is the most $\mathrm{pH}$-resistant species and the dominant population in wines with a pH of below 3.5 (Drici-Cachon et al., 1996; Guzzo et al., 2002). None of the isolated strains showed an RAPDPCR profile similar to that of the commercial strains used in the same wineries (data not shown). Several strains appeared always to be involved in MLF, and a particular pool or mix of strains 


\section{TABLE 5}

Frequencies (number of times out of eight MLF trials) of strains isolated from wine at the end of laboratory malolactic fermentation tests inoculated with a multi-strain $O$. oeni culture. Strains were typed by RAPD-PCR using primers M13, PC1 and GTG5.

\begin{tabular}{|c|c|c|c|c|c|}
\hline & & PN4 & PN3 & T14 & Other strains \\
\hline \multirow{8}{*}{ Test description } & Standard & 6 & 2 & - & 2 \\
\hline & Temperature $-\left(15^{\circ} \mathrm{C}\right)$ & 4 & 3 & 3 & - \\
\hline & $\mathrm{pH}-(3.1)$ & 5 & 2 & 3 & - \\
\hline & $\mathrm{pH}+(3.5)$ & 2 & 4 & 4 & - \\
\hline & Ethanol - (11.2\%) & 6 & 1 & 1 & 1 \\
\hline & Ethanol $+(13.7 \%)$ & 6 & 3 & - & 1 \\
\hline & $\mathrm{SO}_{2}+(40 \mathrm{mg} / \mathrm{L})$ & 7 & 1 & 1 & 1 \\
\hline & $\mathrm{SO}_{2}++(60 \mathrm{mg} / \mathrm{L})$ & 2 & 2 & - & 6 \\
\hline
\end{tabular}

was found in each winery. In many cases, four or five different strains were detectable at the end of MLF, and in wineries where different wines were sampled (wineries $\mathrm{T}$ and $\mathrm{S}$ ) the same strains were found in different tanks (Table 3). These data suggest the presence of a particular $O$. oeni population in each winery, and further research needs to be done to define the role of this microflora in the final wine composition.

In order to better understand the specific effects of each limiting factor, the impact of $\mathrm{SO}_{2}$, ethanol content, wine $\mathrm{pH}$ and fermentation temperature were tested independently (Fig. 3). The data collected suggest that limiting factors have a bacteriostatic effect within the ranges considered (Table 4): in all trials the final cell density reached was at least $10^{8} \mathrm{CFU} / \mathrm{mL}$, but it appeared to be closely linked to differences in the composition of the medium. As expected, strains grew faster under more favourable conditions $\left(\mathrm{pH} 3.5,22^{\circ} \mathrm{C}, 10 \%\right.$ ethanol), and reached $10^{9} \mathrm{CFU} / \mathrm{mL}$ in no more than 10 days. In the tests performed at a $\mathrm{pH}$ of below 3.3, the growth of $O$. oeni strains was limited, as previously found by Guzzo et al. (1988) and Liu and Gallander (1983). Nevertheless, under these limiting conditions the particular resistance of some bacteria became more evident: strains M1, S15 and S44 were able to tolerate $\mathrm{pH} 3.3$ and grew better than the other strains. It is worth noting that the same strains also demonstrated better tolerance to low fermentation temperature: their growth was not affected at $15^{\circ} \mathrm{C}$.

In recent years, climate change and winemaking practices have frequently led to wines with ethanol contents of higher than $13 \%$. The strains tested showed good resistance to high ethanol concentration, given that several of them grew in the presence of up to $16 \%$ ethanol, although Alegria et al. (2000) and Izquierdo et al. (2004) observed a considerable reduction in O. oeni malolactic activity between $13.0 \%$ and $13.5 \%$ alcohol.

Sulphur dioxide is commonly added to wine before alcoholic fermentation to prevent grape must oxidation and spoilage by indigenous microbiota. Its use has to be controlled strictly because $\mathrm{SO}_{2}$, even at a low concentration, has a severe bacteriostatic effect on the LAB microflora and can cause MLF to get stuck (Guzzo et al., 1998; Reguant et al., 2005). Sulphur dioxide is particularly dangerous because the yeast involved in alcoholic fermentation may produce additional $\mathrm{SO}_{2}$, increasing the inhibitory effect on the LAB microflora (Costello et al., 2003; Comitini \& Ciani, 2007). The majority of the strains tested did not produce lactic acid at $\mathrm{SO}_{2}$ concentrations of $60 \mathrm{mg} / \mathrm{L}$; only PN4, PN3, T13 and T414 were able to resist. Considering that $\mathrm{SO}_{2}$ concentrations that allow LAB survival commonly range from 30 to $50 \mathrm{mg} / \mathrm{L}$ (Guzzo et al., 1998, Reguant et al., 2005), it is important to emphasise the fermentative activity of the tested strains.

The large set of data obtained by the $O$. oeni physiological tests was processed by cluster analysis and principal component analysis (PCA) in order to obtain further information about the particular resistance properties of each strain. The results differentiated three groups of bacteria, each of which showed a peculiar resistance to the limiting factors with respect to the considered bacteria population: high $\mathrm{SO}_{2}$ resistance characterised the first group, comprising strains PN4 and T13; the second group (P1, PN3, S13, T11 and T14) was more dispersed, but we can speculate that it was characterised by higher resistance to ethanol; while the third group (M1, S15 and S44) appeared most resistant to low $\mathrm{pH}$ and temperature. The two statistical methods used resulted in the same strain grouping, suggesting that the experimental data provided reliable information about the specific properties of each strain group.

\section{o. oeni MLF performance in wine}

The main objective of this work was the selection of an effective MLF starter strain with high adaptability to resist particularly hostile wine environments. A multi-strain culture composed of six strains chosen in equal proportion from the three groups previously described was used to inoculate the experimental malolactic fermentations. As reported in Table 1, these tests were carried out in a base wine by changing one limiting factor at a time. At a lower selective pressure the MLFs were faster, as observed in wines with a $\mathrm{pH}$ of 3.5 or ethanol concentrations below $11.5 \%$. Fast fermentations were also observed when the ethanol concentration was increased to up to $13.7 \%$, or when the fermentation temperature was lowered to $15^{\circ} \mathrm{C}$. The multistrain culture showed a prolonged lag phase only at the lowest $\mathrm{pH}$ (3.1) or at a high $\mathrm{SO}_{2}$ concentration, but the total duration of fermentation was comparable with those carried out in more favourable conditions. The use of a multi-strain starter could be useful, as it allows growth of the strain(s) that are better adapted to whichever limiting factors may be present.

RAPD-PCR typing of the strains isolated from the wines after MLF highlighted the presence of at least three strains out of the 
TABLE 6

Duration of MLF in wines inoculated with $O$. oeni PN4 compared with two commercial strains (Com1 and Com2) and indigenous microflora (IM).

\begin{tabular}{|c|c|c|c|c|c|c|c|c|c|}
\hline \multirow{2}{*}{ MLF } & \multirow{2}{*}{ Country } & \multirow{2}{*}{ Wine } & \multirow{2}{*}{$\begin{array}{c}\text { Ethanol } \\
(\%)\end{array}$} & \multirow{2}{*}{ pH } & \multirow{2}{*}{$\begin{array}{c}\text { Total SO } \\
(\mathrm{g} / \mathrm{L})\end{array}$} & \multicolumn{4}{|c|}{ MLF duration (days) } \\
\hline & & & & & & PN4 & Com1 & Com2 & IM \\
\hline 1 & Germany & Riesling & 12.0 & 3.05 & nd & 19 & sf & - & sf \\
\hline 2 & Germany & Pinot noir & 13.2 & 3.37 & nd & 12 & 16 & - & 16 \\
\hline 3 & Germany & Pinot noir & 13.1 & 3.40 & 40 & 8 & 10 & - & 10 \\
\hline 4 & Germany & Lemberger & 13.5 & 3.30 & nd & 17 & 17 & - & - \\
\hline 5 & USA & Merlot & 14.0 & 3.27 & 60 & 28 & - & 32 & sf \\
\hline 6 & USA & Merlot & 14.2 & 3.50 & 60 & 13 & - & 34 & - \\
\hline 7 & Italy & Garganega & 13.2 & 3.25 & nd & 18 & 25 & - & 28 \\
\hline 8 & Italy & Sangiovese & 14.0 & 3.33 & nd & 21 & 21 & - & sf \\
\hline 9 & Italy & Sangiovese & 14.9 & 3.21 & 60 & 59 & 90 & - & sf \\
\hline 10 & Italy & Sangiovese & 15.8 & 3.50 & 20 & 49 & sf & - & sf \\
\hline 11 & Italy & Chardonnay & 11.6 & 3.00 & 40 & 25 & - & - & - \\
\hline 12 & Italy & Lagrein & 13.5 & 3.62 & 30 & 19 & - & - & - \\
\hline 13 & Italy & Merlot & 12.4 & 3.30 & 30 & 18 & 18 & - & - \\
\hline 14 & Italy & Rebo & 13.4 & 3.76 & 20 & 30 & - & - & - \\
\hline 15 & Italy & Rebo & 14.6 & 3.70 & 60 & 22 & 31 & - & - \\
\hline 16 & Italy & Teroldego & 12.6 & 3.63 & 40 & 11 & - & - & - \\
\hline 17 & Italy & Teroldego & 12.6 & 3.62 & 50 & 15 & - & - & - \\
\hline
\end{tabular}

s.f.: stuck fermentation, i.e. malic acid concentration $\geq 1 \mathrm{~g} / \mathrm{L}$ after 40 days. nd: data not available. - : test not performed.

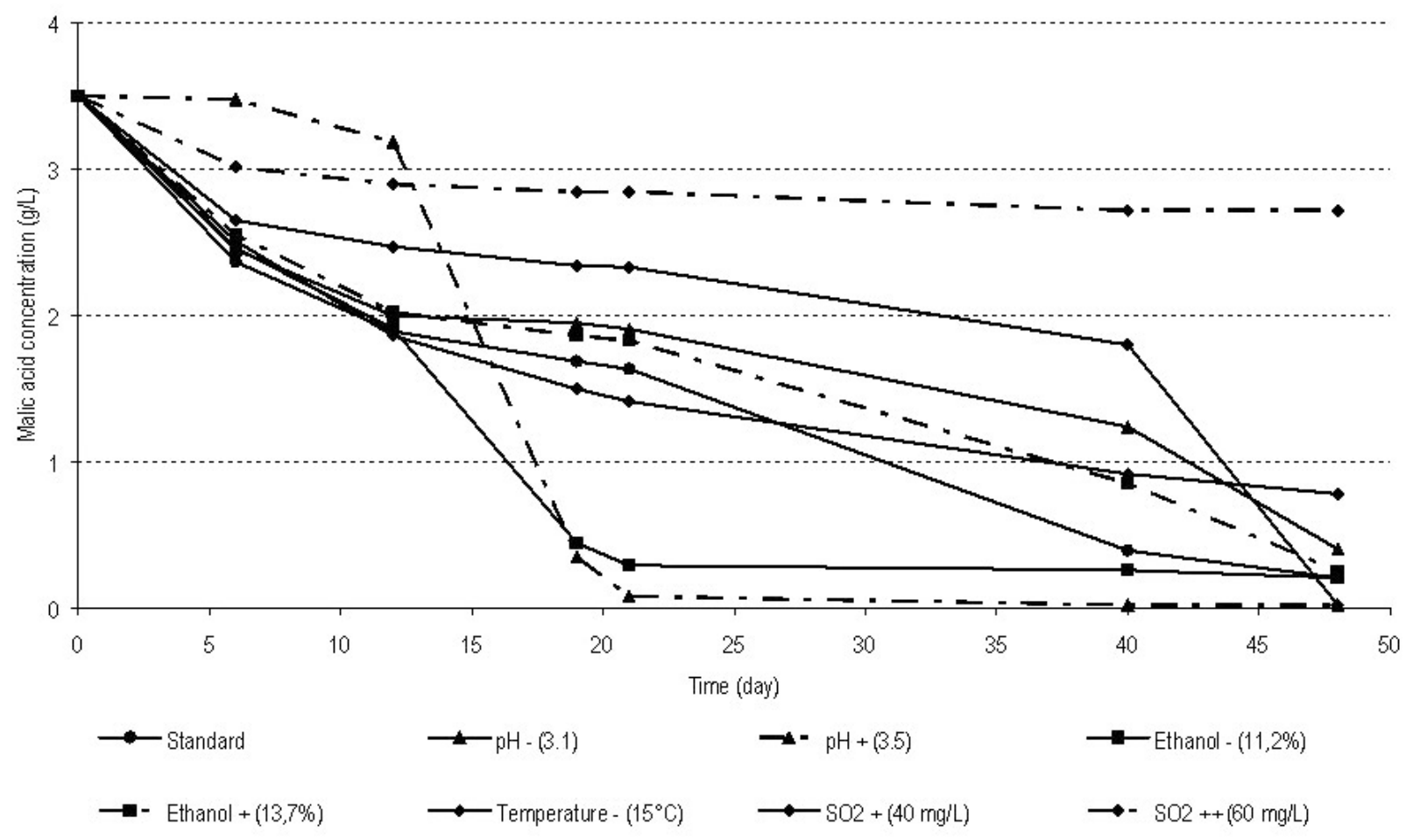

FIGURE 3

Malic acid degradation curves of eight laboratory wine MLF trials, each one inoculated with the same $O$. oeni multi-strain culture. The multi-strain culture, composed of strains T13, T14, M1, S44, PN3 and PN4, was tested in different wine conditions. 


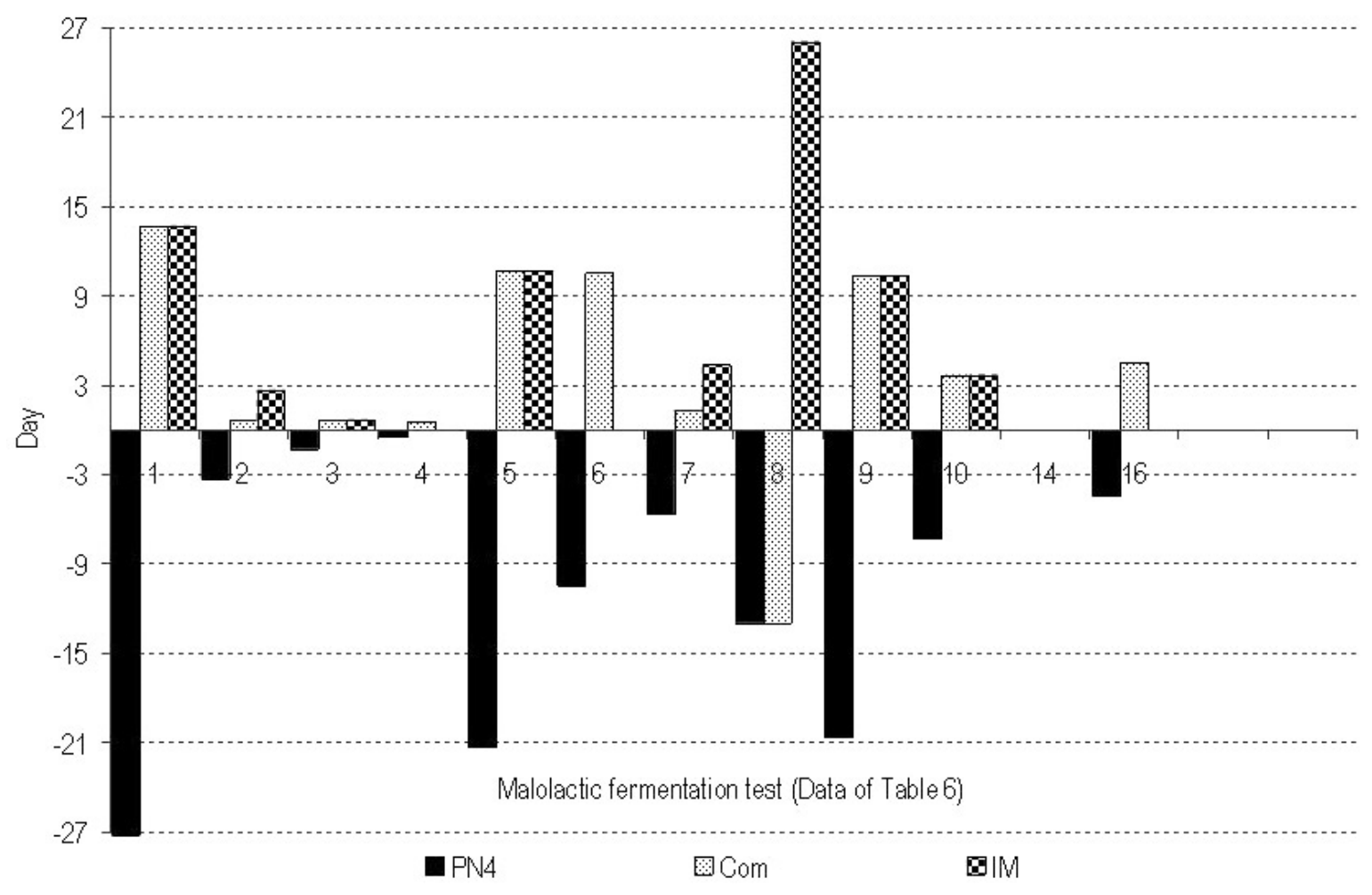

FIGURE 4

Differences from the mean MLF durations of MLFs performed by PN4, commercial strain and indigenous strain, tested in wine (Data of Table 6). The PN4 strain showed the highest fermentation rate and the lowest percentage of stuck fermentations.

six inoculated. The PN4 strain appeared to be the most promising of the inoculated bacteria, being dominant in five fermentations, in particular when $\mathrm{pH}$, ethanol and sulphur dioxide levels were most harmful. Its effectiveness was therefore tested in a large set of winery-scale MLFs under commercial conditions.

MLF driven by PN4 was compared with MLF induced by two commercial $O$. oeni strains in wines having at least one of the relevant limiting factors. In the wines made in Germany (MLFs 1-4 in Table 6), the $\mathrm{pH}$ values and fermentation temperatures were very low. Under these conditions the PN4 strain showed the highest MLF rate among the bacteria starter cultures used, adapting well to northern wine conditions. In the two wines from the USA, the bacteria were tested in high ethanol and $\mathrm{SO}_{2}$ concentrations. Despite the limiting conditions, PN4 accomplished MLF fast, whereas fermentation became stuck in wines fermented by indigenous bacteria. The data collected from the malolactic fermentations in northern and central Italy confirmed previous findings: a general delay in the onset of MLF was observed when ethanol exceeded $12.5 \%$. Among the variables directly controlled by the winemaker (fermentation temperature, the addition of sulphur dioxide), $\mathrm{SO}_{2}$ concentration was the most detrimental to bacterial activity.

Figure 4 shows the differences between the average duration of MLF with the three different starters (PN4, commercial strains and indigenous microflora). Despite the different properties of the individual wines, a general trend appears. The PN4 strain fermented faster than the other bacteria in most wine conditions and resulted in a higher percentage of successful MLFs. Taking into consideration only the trials in which MLF was completed in less than 20 days, $76 \%$ of those driven by PN4 were successful, against $42 \%$ of those driven by other commercial strains and $25 \%$ by indigenous microflora. Tests 9 and 10 (Table 6) were exceptions to the high PN4 fermentation rate, probably because they were carried out in wines with the highest ethanol concentrations. Although requiring almost 50 days to complete MLF, PN4 was the only strain able to accomplish complete malic acid degradation in these conditions.

It is possible to conclude that, despite considerable variation in wine conditions and the concurrent presence of many harmful parameters in the considered wines, the PN4 strain always fermented faster than the commercial strains or native wine microflora, which frequently became stuck.

\section{CONCLUSIONS}

A procedure for selecting LAB strains from spontaneous MLFs in Trentino wineries revealed a high biodiversity in LAB strains driving MLF. A pool of 22 strains was found and tested for resistance to harsh environmental conditions in wine. The six most resistant strains were used in multi-strain wine inoculation in the laboratory. The trials showed the particular aptitude of strain PN4 always to perform fast and complete MLFs. Seventeen MLF trials were conducted in various wineries throughout the world using PN4 in pure culture for direct inoculation, and its activity was compared with other commercial strains and spontaneous MLFs. The laboratory results were confirmed on a larger scale, showing that PN4 always acted faster and completed the degradation of malic acid ahead of other strains. These results also suggest the 
usefulness of further research using a multi-strain inoculation approach that is able to emulate spontaneous MLF under winery conditions, where a mix of autochthonous strains is involved in malic acid degradation, leading to dominance of the strains best adapted to the wine conditions.

\section{LITERATURE CITED}

Atlas, R.M., 2004. Handbook of microbiology media (ed. Lawrence C. Parks). CRC Press, Boca Raton (Florida). p. 758.

Bartowsky, E.J. \& Henschke, P.A., 1999. Use of a polymerase chain reaction for specific detection of the malolactic fermentation bacterium Oenococcus oeni (formerly Leuconostoc oenos) in grape juice and wine samples. Aust. J. Grape Wine Res. 5, 39-44.

Bauer, R. \& Dicks, L.M.T., 2004. Control of malolactic fermentation in wine. A review. S. Afr. J. Enol. Vitic. 25(2), 74-87.

Carrete, R., Reguant, C., Rozes, N., Constanti, M. \& Bordons, A., 2006a. Analysis of Oenococcus oeni strains in simulated microvinifications with some stress compounds. Am. J. Enol. Vitic. 57(3), 356-362.

Carrete R., Vidal M.T., Bordons A. \& Constanti, M., 2006b. Inhibitory effect of sulfur dioxide and other stress compounds in wine on the ATPase activity of Oenococcus oeni. FEMS Microbiol. Lett. 211(2), 155-159.

Comitini, F. \& Ciani, M., 2007. The inhibitory activity of wine yeast starters on malolactic bacteria. Ann. Microbiol. 57(1), 61-66.

Costello, P.J., Henschke, P.A. \& Markides, A.J. 2003. Standardized methodology for testing malolactic bacteria and wine yeast compatibility. Aust. J. Grape Wine Res. 9, 127-137.

Coucheney, F., Desroche, N., Bou, M., Tourdot-Marechal, R., Dulau, L. \& Guzzo, J., 2005. A new approach for selection of Oenococcus oeni strains in order to produce malolactic starters. Int. J. Food Microbiol. 105(3), 463-470.

Da Silveira, M.G., Baumgartner, M., Rombouts, F.M. \& Abee, T., 2004. Effect of adaptation to ethanol on cytoplasmic, and membrane protein profiles of Oenococcus oeni. Appl. Environ. Microbiol. 70(5), 2748-2755.

Davis, C.R., Wibowo, D., Lee, T.H. \& Fleet, G.H., 1988. Properties of wine lactic acid bacteria: their potential oenological significance. Am. J. Enol. Vitic. 39, 137142 .

Drici-Cachon, Z., Guzzo, J., Cavin, J.F.\& Divies C., 1996. Acid tolerance in Leuconostoc oenos. Isolation and characterization of an acid-resistant mutant. Appl. Microbiol. Biotechnol. 44, 785-789.

G-Alegria, E., Lopez, I., Ruiz, J.I., Saenz, J., Fernandez, E., Zarazaga, M., Dizy, M., Torres, C. \& Ruiz-Larrea, F. 2000. High tolerance of wild Lactobacillus plantarum and Oenococcus oeni strains to lyophilisation and stress environmental conditions of acid pH and ethanol. FEMS Microbiol. Lett. 230(1), 53-61.

Giraffa, G., Rossetti, L. \& Neviani, E., 2000. An evaluation of chelex-based DNA purification protocols for the typing of lactic acid bacteria. J. Microbiol. Met. 42(2), 175-184.

Guzzo, J., Coucheney, F., Pierre, F., Fortier, L., Delmas, F., Dives, C. \& TourdotMaréchal, R., 2002. Acidophilic behavior of the malolactic bacterium Oenococcus oeni. Sci. Alim. 22(1-2), 107-111.

Guzzo, J., Jobin, M.P. \& Divies, C., 1998. Increase of sulphite tolerance in Oenococcus oeni by means of acidic adaptation. FEMS Microbiol. Lett. 160, 143147.
Guzzon, R., Poznanski, E., Zini, C. \& Cavazza, A., 2007. Batteri malolattici con alta resistenza a fattori limitanti: una selezione da vini trentini. L'Enologo 6, 1-5.

Henick-Kling, T., 1993. Malolactic fermentation. In: Fleet, G.H. (ed.). Wine microbiology and biotechnology. Harwood Academic, Chur (S). pp. 290-326.

Izquierdo, P.M., Garcia, E., Martinez, J. \& Chacon, J.L., 2004. Selection of lactic bacteria to induce malolactic fermentation in red wine of $c v$. Cencibel. Vitis 43(3), $149-153$.

Liu, J.W.R. \& Gallander, J.F., 1983. Effect of $\mathrm{pH}$ and sulfur dioxide on the rate of malolactic fermentation in red table wines. Am. J. Enol. Vitic. 34(1), 44-46.

Liu, S.Q., 2002. Malolactic fermentation in wine. Beyond deacidification. J. Appl. Microbiol. 92, 589-601.

Lonvaud-Funel, A. 1999. Lactic acid bacteria in the quality improvement and appreciation of wine. Antonie van Leeuwenhoek 76, 317-331.

Pozo-Bayon, M.A., Alegria, E.G., Polo, M.C., Tenorio, C., Martín-Álvarez, P.J. \& Calvo de la Banda, M.T., 2005. Wine volatile and amino acid composition after malolactic fermentation. Effect of Oenococcus oeni and Lactobacillus plantarum starter cultures. J. Agric. Food Chem. 53(22), 8729-8735.

Reguant, C., Carrete, R., Constanti, M. \& Bordons, A., 2005. Population dynamics of Oenococcus oeni strains in a new winery and the effect of $\mathrm{SO}_{2}$ and yeast strain. FEMS Microbiol. Lett. 246(1), 111-117.

Renouf, V., Gindreau, E., Claisse, O. \& Lonvaud-Funel, A., 2005. Microbial changes during malolactic fermentation in red wine elaboration. J. Int. Sci. Vigne Vin. 39(4), 179-190.

Renouf, V., Miot-Sertier, C., Strehaiano, P. \& Lonvaud-Funel, A., 2006. The wine microbial consortium. A real terroir characteristic. J. Int. Sci. Vigne Vin. 40(4), 209-216.

Ribéreau-Gayon, P., Dubourdieu, D., Doneche, B. \& Lonvaud, A., 2004. In: Dunod (ed.) Traité d'oenologie, Tome 1: Microbiologie du vin, Vinifications. Paris (F).

Rosi, I., Fia, G. \& Canuti, V., 2003. Influence of different $\mathrm{pH}$ values and inoculation time on the growth and malolactic activity of a strain of Oenococcus oeni. Aust. J. Grape Wine Res. 9, 194-199.

Teixeira, H., Goncalves, M.G., Rozes, N., Ramos, A. \& San Romao, M.V., 2002. Lactobacillic acid accumulation in the plasma membrane of Oenococcus oeni: a response to ethanol stress? Microb. Ecol. 43(1): 146-153.

Ugliano, M. \& Moio, L., 2007. Malolactic fermentation and wine flavours: changes in the volatile composition of red wine following malolactic fermentation with four commercial strains of Oenococcus oeni. Aust. N. Z. Grape Grow. Winemaker 521a, 53-56.

Versalovic, J., Schneider, M., De Bruijn, F.J. \& Lupski, J.R., 1994. Genomic fingerprinting of bacteria using repetitive sequence-based polymerase chain reaction. Meth. Mol. Cell. Biol. 5(1), 25-40.

Wibowo, D., Eschenbruch, R., Davis, C.R., Fleet, G.H. \& Lee, T.H., 1985. Occurrence and growth of lactic acid bacteria in wine: a review. Am. J. Enol. Vitic. 36(4), 302-313.

Zapparoli, G., Torriani, S., Pesente, P. \& Dell'aglio, F., 1998. Design and evaluation of malolactic enzyme gene targeted primers for rapid identification and detection of Oenococcus oeni in wine. Lett. Appl. Microbiol. 27, 243-246.

Zapparoli, G., Tosi, E. \& Krieger, S., 2006 Influence of the pH of Chardonnay must on malolactic fermentation induced by bacteria co-inoculated with yeasts. Vitis 45(4), 197-198. 